\title{
Production and characterization of a new dextrin based hydrogel
}

\author{
Joana Carvalho ${ }^{\text {a }}$, Catarina Gonçalves ${ }^{\text {a }}$, Ana M. Gil ${ }^{\text {b }}$, Francisco M. Gama ${ }^{\text {a,* }}$ \\ a Centro de Engenharia Biológica, Universidade do Minho, Campus de Gualtar, 4710-057 Braga, Portugal \\ b Departamento de Química, Universidade de Aveiro, Campus de Santiago, 3810-193 Aveiro, Portugal
}

Received 12 December 2006; received in revised form 27 February 2007; accepted 28 February 2007

Available online 21 April 2007

\begin{abstract}
Dextrin is a polymer composed of $\alpha-(1 \rightarrow 4)$ D-glucose units produced by partial hydrolysis of starch. In this work, the transesterification of the soluble polysaccharide with vinyl acrylate (VA) was carried out in anhydrous dimethylsulfoxide (DMSO). The effect of the water activity and of the enzyme Proleather, on the reaction rates, was analysed. Different degrees of substitution (DS) ranging from ca. 10\% to $70 \%$ were obtained by controlling the molar ratio of VA to dextrin. Gels were obtained by free radical polymerization of dextrin-VA, with different degrees of substitution and monomer concentration, in water. A comprehensive solid state-NMR analysis of the hydrogels was performed. These hydrogels are being developed as scaffold materials for bioactive molecule and cell delivery, tissue engineering and a variety of other biomedical applications.
\end{abstract}

(c) 2007 Elsevier Ltd. All rights reserved.

Keywords: Dextrin; Enzyme; Transesterification; Vinyl acrylate (VA); Hydrogels

\section{Introduction}

Hydrogels are a class of three-dimensional, highly hydrated polymeric networks [1]. They are composed of hydrophilic polymer chains, which can be either synthetic or natural. The structural integrity of hydrogels depends on cross-links established between the polymer chains, by chemical bonds and physical interactions. Hydrogels are providing new opportunities for the development of a variety of medical applications [2], including drug delivery systems [3], scaffold materials to organize cells into a three-dimensional architecture, tissue

\footnotetext{
* Corresponding author. Tel.: +35 1253604418; fax: +35 1253678986.

E-mail address: fmgama@deb.uminho.pt (F.M. Gama).
}

replacements [4], wound dressings [5,6] and immobilization of proteins and cells, among others. Since the clinical use of hydrogels is increasing, considerable efforts have been made in order to develop new hydrogels from a variety of synthetic and natural materials [7]. In this work, we report a procedure to prepare dextrin hydrogels. Dextrin is a glucosecontaining saccharide polymer linked by $\alpha-(1 \rightarrow 4)$ D-glucose units, having the same general formula as starch, but smaller and less complex. This polysaccharide is produced by partial hydrolysis of starch, which can be accomplished by the use of acid, enzymes, or a combination of both. Dextrin is a widely used material with a variety of applications, from adhesives to food industry and textiles. Moreover, because of the biocompatibility and degradability, starch-based materials are presently 
being used to prepare biodegradable hydrogels with technological applications in a large number of areas such as medicine, pharmacy and biology $[8,9]$. Various approaches have been already explored for the production of starch hydrogels. These approaches include one or two-step free radical graft polymerization of hydrophilic vinyl monomers in the presence of a cross-linker, cross-linking b y chemical reactions with complementary groups, radiation-induced polymerization and cross-linking, and novel self-assembly processes [10]. However, compared with our approach, some of these chemical strategies show disadvantages, such as the use of catalysts (e.g. 4-dimethylaminopyridine (4-DMAP) or pyridoxine) $[11,12]$ which are difficult to remove from the reaction mixture and could dramatically increase the toxicity of the material.

To prepare the hydrogels, dextrin was modified with vinyl acrylate (VA) using two different approaches, chemical or enzymatic. Chemical synthesis is broadly used, however presenting several drawbacks, such as the need for protection and deprotection of functional groups to prevent unwanted racemization, as well as the lack of stereoselectivity. The use of enzymes under mild conditions has allowed, in some cases, overcoming these limitations, also enabling modification of molecules that could not otherwise be altered [13-16]. Apolar solvents are generally considered to better preserve the enzymatic activity that polar ones $[17,18]$. However, Ferreira et al. [11,12] have recently reported the used of the Bacillus subtilis protease Proleather FG-F to catalyze the transesterification of dextran with VA, in anhydrous dimethylsulfoxide (DMSO). The enzyme-catalyzed system developed by Ferreira and colleagues, using dextran and inulin, was in this work used for dextrin modification. The starch polysaccharide functionalized with reactive double bonds was cross-linked by free radical polymerization in aqueous solution. The structure and morphology of starch networks in the hydrogel were characterized by cross-polarization magic-anglespinning ${ }^{13} \mathrm{C}$ NMR spectroscopy (CP-MAS ${ }^{13} \mathrm{C}$ NMR).

\section{Experimental section}

\subsection{Materials}

Proleather FG-F, a protease from B. subtilis, was obtained from Amano Enzyme Co. Dextrin-Koldex $60\left(M_{\mathrm{w}}=45700 \mathrm{Da}\right.$, as determined by gel perme- ation chromatography (GPC) analysis) was a generous gift from Tate \& Lyle. Vinyl acrylate (VA) was from Aldrich, $N, N, N^{\prime}, N^{\prime}$-tetramethylenethylenediamine (TEMED) and ammonium persulfate (APS) were purchased from BioRad, dimethylsulfoxide (DMSO) and acetone were from AppliChem and polyethyleneglicol (PEG $200 \mathrm{~g} / \mathrm{mol}$ ) was obtained from Riedel-d Haën. DMSO was dried with $0.4 \mathrm{~nm}$ molecular sieves, at least overnight, before use. Regenerated cellulose tubular membranes, with $3500 \mathrm{MWCO}$, were obtained from membrane filtration products.

\subsection{Pretreatment of Proleather and determination of proteolytic activity in DMSO}

Proleather FG-F was " $\mathrm{pH}$ adjusted" as described by Ferreira et al. [11,12]. The enzyme was resuspended in $20 \mathrm{mM}$ phosphate buffer at $\mathrm{pH}$ 8. After freezing, the sample was lyophilized on a CHRIST ALPHA2-4 lyophization unit (B. Braun Biotech International) for $48 \mathrm{~h}$. The percentage of active enzyme in commercial powder was $8.9 \%(\mathrm{w} / \mathrm{w})$ as obtained by BCA Protein Assay (Pierce) using BSA as protein standard. The proteolytic activity of Proleather FG-F in either $0.2 \mathrm{M}$ phosphate buffer pH 8 or DMSO was determined with casein as substrate. Briefly, in the presence of a protease the casein is cleaved, exposing primary amines. The compound TNBSA (2,4,6-trinitrobenzene sulfonic acid) reacts with these exposed amines thereby producing an orange-yellow colour that can be quantified as $450 \mathrm{~nm}$ absorbance. Control blanks for each sample were included in the assay to correct the effect of primary amines on proteins in the protease sample. The absorbance values were then converted to equivalent subtilisin (a B. subtilis protease) concentration using a calibration curve. One unit of protease activity (U) is defined as the production of $1 \mathrm{mM}$ of free amine per minute per milligram of enzyme.

\subsection{Enzymatic and chemical synthesis of dextrin-VA}

The enzyme-catalyzed modification of dextrin was performed as described by Ferreira et al. $[11,12]$, with few modifications. Briefly, dextrin $(4 \mathrm{~g})$ and an amount of VA ranging from 382 to $2600 \mu \mathrm{L}$ were dissolved in anhydrous DMSO $(60 \mathrm{~mL})$. The reaction was started by adding $600 \mathrm{mg}$ of " $\mathrm{pH}$ adjusted" Proleather FG-F. The reaction mixtures were then incubated at $50{ }^{\circ} \mathrm{C}$, 


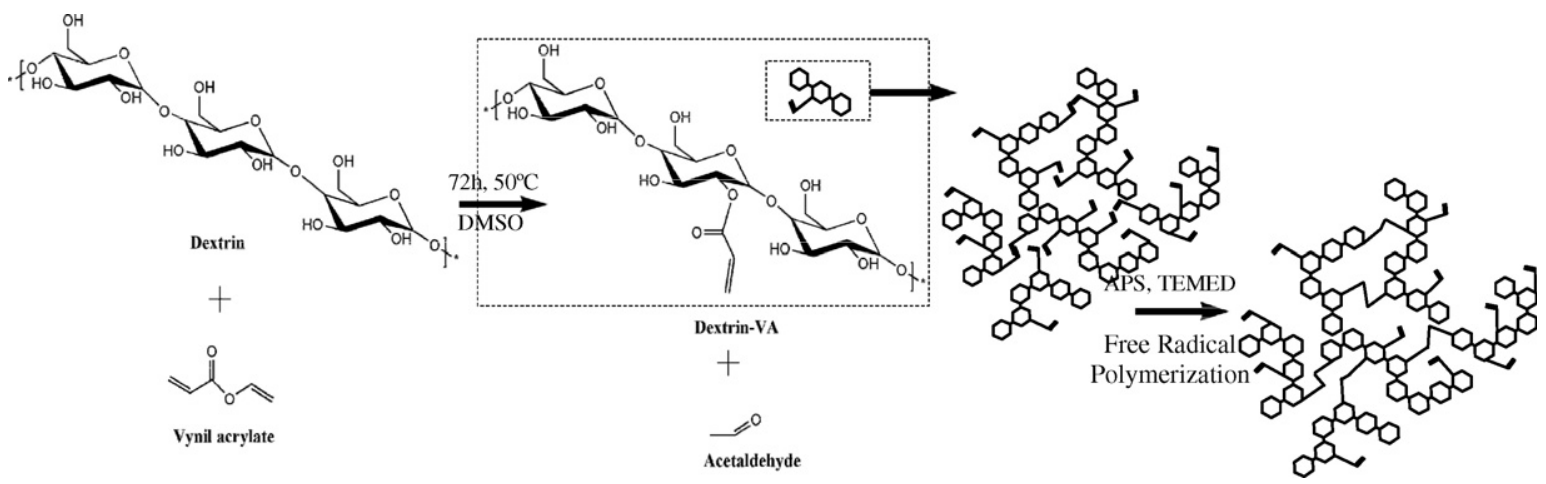

Fig. 1. Dextrin-VA synthesis and formation of the hydrogel networks.

with magnetic stirring, for $72 \mathrm{~h}$. Fig. 1 shows the chemical reaction of dextrin modification. After this time, the mixtures were dialyzed for 5 days against $\mathrm{HCl}$ aqueous solution, $\mathrm{pH} 3$, at $4{ }^{\circ} \mathrm{C}$. The aqueous solutions of dextrin-VA were precipitated in a 4-fold excess of acetone and further centrifuged at $9000 \mathrm{rpm}$ for $15 \mathrm{~min}$. Finally, the precipitates were lyophilized for $48 \mathrm{~h}$. The chemical modification was carried out in the same conditions, but in the absence of enzyme.

The degree of substitution (DS, defined as the amount of acrylate groups per 100 glucopyranose residues) was determined by titration according to Vervoort et al. [19]. Dextrin-VA samples (100 mg) were dissolved in $2.00 \mathrm{~mL}$ of $0.1 \mathrm{M} \mathrm{NaOH}$ (standardised) and stirred for $72 \mathrm{~h}$ at room temperature, to carry out the alkaline hydrolysis of the ester. Molar consumption of $\mathrm{NaOH}$ was determined by back titration with $0.1 \mathrm{M}$ (standardised) $\mathrm{HCl}$, using phenolphthalein as indicator. Additionally, a liquid RMN analysis of the DS was also performed and the values compared.

\subsection{Determination of water amount and activity $\left(a_{w}\right)$}

Water content was determined by the Karl Fisher titration method. Water activity of DMSO solutions with different amounts of water was established using a microclimate method. A small amount of sample is disposed in a plate as a thin layer. The plate is then placed in a gas-tight container, where relative humidity is fixed with saturated salt solutions ( $\mathrm{LiCl}, \mathrm{MgCl}_{2}, \mathrm{KI}$ and $\left.\left(\mathrm{NH}_{4}\right)_{2} \mathrm{SO}_{4}\right)$. Whenever the sample and the saturated salt solutions do not have the same water activity, a water transfer among the samples occurs, quantified by weighting.

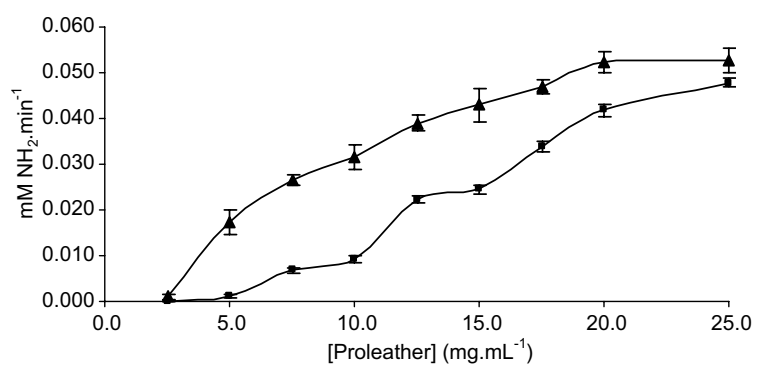

Fig. 2. Proteolytic activity in $0.2 \mathrm{M}$ phosphate buffer $\mathrm{pH} 8(\boldsymbol{\Delta})$ or DMSO (ם) using casein as substrate. The proteolytic activity is expressed as the rate of $\mathrm{NH}_{2}$ formation.

The equilibrium is reached when constant mass is observed, by sorption or desorption. The water activity of the sample is determined according to the procedure described by Multon and Bizot [20] and shown in Fig. 2.

\subsection{Preparation of dextrin-VA hydrogels}

Dextrin-VA hydrogels were obtained by free radical polymerization of aqueous solution of dextrinVA, with different degrees of substitution and monomer concentration (Fig. 1). Two different amounts of dextrin-VA (300 and $400 \mathrm{mg}$ ) were dissolved in $900 \mu \mathrm{L}$ of $0.2 \mathrm{M}$ phosphate buffer, $\mathrm{pH}$ 8.0, and bubbled with nitrogen for $2 \mathrm{~min}$. The gelation reactions were initiated by adding $90 \mu \mathrm{L}$ APS $(80 \mathrm{mg} / \mathrm{ml}$ in $0.2 \mathrm{M}$ phosphate buffer, $\mathrm{pH} 8.0)$ and $90 \mu \mathrm{L}$ TEMED $(13.6 \%(\mathrm{v} / \mathrm{v})$ in water, $\mathrm{pH}$ adjusted to 8.0 with $\mathrm{HCl}$ ) and allowed to occur for $30 \mathrm{~min}$ at room temperature. All the recipients in which gelation took place were coated with a polyethyleneglicol solution (PEG $200 \mathrm{~g} / \mathrm{mol}$ ) to simplify the removal of the hydrogel following polymerization. 


\subsection{Solid state NMR spectroscopy}

The CP-MAS ${ }^{13} \mathrm{C}$ NMR technique is a convenient solid-state analytical method for the characterization of hydrogels due to the insolubility of their networks. The ${ }^{13} \mathrm{C}$ NMR spectra were recorded on a $400 \mathrm{MHz}$ Bruker FT NMR (Fourier transform nuclear magnetic resonance) spectrometer equipped with CP-MAS (cross-polarization and magic-angle-spinning) accessories. The dry samples were placed in a $7 \mathrm{~mm}$ rotor and spun at a rate of $4.5 \mathrm{kHz}$. Spectra were acquired with a contact time of $5 \mathrm{~ms}$, spectral width $300 \mathrm{ppm}, 2 \mathrm{~K}$ time domain points and the number of transients indicated in the figure captions. All spectra were processed with a linebroadening (LB) factor of $30 \mathrm{~Hz}$ in order to improve signal to noise ratio.

\subsection{X-ray powder diffraction measurements}

Monochromatic $\mathrm{Cu}-\mathrm{K}_{\alpha}$ radiation (wavelength $=$ $1.542 \AA$ A ) was produced by a Philips PW1710 X-ray powder diffractometer. The samples were exposed to the $\mathrm{X}$-ray beam with the $\mathrm{X}$-ray generator running at $40 \mathrm{kV}$ and $30 \mathrm{~mA}$. The scanning regions of the diffraction angle $2 \theta$ were $3-65^{\circ}$, step interval 0.02 and scan rate $2{ }^{\circ} \mathrm{C} / \mathrm{min}$.

\section{Results and discussion}

\subsection{Production of dextrin-VA}

In previous studies, Ferreira et al. [12] demonstrated the successful enzymatic acryloilation of the polysaccharide dextran, solubilized in anhydrous DMSO. In this work, a similar dextrin modification was attempted using the same enzyme- catalyzed method. The proteolytic activity of the enzyme Proleather FG-F in either $0.2 \mathrm{M}$ phosphate buffer $\mathrm{pH} 8$ or DMSO was assessed (Fig. 2). As can be seen, although with a smaller activity, the enzyme remains catalytically active when solubilized in a DMSO solution. Additionally, a time-course reaction, carried out for six days, showed that the enzyme is very stable in DMSO, conserving nearly $80 \%$ of the initial activity.

The synthesis of dextrin-VA was performed both in the presence or absence of $10 \mathrm{mg} / \mathrm{mL}$ Proleather FG-F, for $72 \mathrm{~h}$ at $50{ }^{\circ} \mathrm{C}$ in DMSO. The results in Table 1 show that dextrin-VA with different DS (ranging from ca. 10\% to $70 \%$ ) can be obtained, both in the presence or absence of the enzyme, by varying the concentration of the acyl donor. The modified polymer was successfully recovered by precipitation with an excess of acetone, after dialysis. The obtained reaction yields, in the range $41-62 \%$, were superior to values referred in other similar works $[11,12]$.

A comparative study, using dextrin and dextran, was carried out in the presence and absence of the enzyme. Dextrans are soluble polysaccharides characterized by a predominance (higher than 95\%) of $\alpha(1 \rightarrow 6)$ backbone linkages and varying proportions of $\alpha(1 \rightarrow 2), \alpha(1 \rightarrow 3)$ and $\alpha(1 \rightarrow 4)$ linkages typically at branch points. Dextrins are partially hydrolyzed glucose homopolymers composed exclusively of $\alpha(1 \rightarrow 4)$ backbone linkages. As already stated, Ferreira et al. showed in previous work that the presence of the Proleather enzyme is mandatory for a high DS to be obtained, using dextran as substrate, as confirmed in this work (Table 1). Interestingly, the spontaneous non-catalysed reaction is very effective in the case of dextrin (reaction efficiency always higher than $59 \%$ ). As a matter of fact,

Table 1

Degree of substitution (DS) obtained with different VA concentrations obtained enzymatic and chemically, with dextrin and dextran as substrates

\begin{tabular}{|c|c|c|c|c|c|c|c|}
\hline \multicolumn{4}{|l|}{ Dextrin } & \multicolumn{4}{|l|}{ Dextran } \\
\hline \multicolumn{2}{|c|}{ With Proleather } & \multicolumn{2}{|c|}{$\begin{array}{l}\text { Non-catalysed reaction } \\
\text { (without Proleather) }\end{array}$} & \multicolumn{2}{|c|}{ With Proleather } & \multicolumn{2}{|c|}{$\begin{array}{l}\text { Non-catalysed reaction } \\
\text { (without Proleather) }\end{array}$} \\
\hline $\mathrm{DS}(\%)^{\mathrm{a}}$ & Efficiency $^{\mathrm{b}}$ & $\operatorname{DS}(\%)^{\mathrm{a}}$ & Efficiency $^{\mathrm{b}}$ & $\operatorname{DS}(\%)^{\mathrm{a}}$ & Efficiency $^{\mathrm{b}}$ & $\operatorname{DS}(\%)^{\mathrm{a}}$ & Efficiency $^{\mathrm{b}}$ \\
\hline 11 & 73 & 10 & 73 & 10 & 67 & 0 & 0 \\
\hline 14 & 70 & 13 & 70 & 13 & 65 & 0 & 0 \\
\hline 19 & 76 & 20 & 76 & 16 & 64 & 0 & 0 \\
\hline 67 & 67 & 59 & 59 & 44 & 44 & 5 & 5 \\
\hline
\end{tabular}


the presence of enzyme, for this substrate, does affect neither the reaction yield nor kinetics. It thus appears that the non-catalysed reaction occurs faster and to a higher extent with dextrin as substrate rather than with dextran. Proleather is an efficient catalyst for dextran transesterification, but not of dextrin. Indeed, the reaction reaches similar conversion degrees for different DS and reaction times (data not shown) irrespective of the presence of enzyme. These results clearly show that, contrarily to previous results obtained with dextran and inulin, dextrin acylation is not catalysed by Proleather.

Table 2

${ }^{13} \mathrm{C}$ and ${ }^{1} \mathrm{H}$ NMR assignments of the glucopyranosyl ring $(\delta, \mathrm{ppm})$ on dextrin-VA with DS $20 \%$

\begin{tabular}{|c|c|c|c|c|c|c|}
\hline \multirow[t]{3}{*}{ Carbon } & \multicolumn{6}{|c|}{ Dextrin-VA } \\
\hline & \multicolumn{2}{|c|}{ Unsubstituted } & \multicolumn{2}{|c|}{ 2-substituted } & \multicolumn{2}{|c|}{ 3-substituted } \\
\hline & ${ }^{1} \mathrm{H}$ & ${ }^{13} \mathrm{C}$ & ${ }^{1} \mathrm{H}$ & ${ }^{13} \mathrm{C}$ & ${ }^{1} \mathrm{H}$ & ${ }^{13} \mathrm{C}$ \\
\hline 1 & 5.42 & 102.4 & 5.65 & 99.06 & 5.47 & 102.30 \\
\hline 2 & 3.65 & 74.26 & 4.86 & 75.53 & $\mathrm{a}$ & \\
\hline 3 & 3.86 & 73.89 & 4.25 & 73.67 & 5.44 & 78.06 \\
\hline 4 & 3.69 & 79.45 & 3.69 & 79.45 & 3.69 & 79.45 \\
\hline 5 & 3.99 & 76.05 & 3.99 & 76.05 & 3.99 & 76.05 \\
\hline 6 & 3.88 & 63.18 & 3.88 & 63.18 & 3.88 & 63.18 \\
\hline
\end{tabular}

${ }^{a}$ Signals not identified.

\subsubsection{Characterization of dextrin-VA obtained with and without Proleather}

The ester positions on the glucopyranosyl residues were determined based on additional signals present in the ${ }^{13} \mathrm{C}$ NMR spectrum of dextrin-VA produced both with and without Proleather [11]. The two positional isomers in the main dextrin backbone are at the glucopyranosyl positions 2 and 3 . The respective ${ }^{13} \mathrm{C} \mathrm{NMR}$ assignments are presented in Table 2.

Bi-dimensional (HSQC) NMR experiments were carried out in order to evaluate the isomer ratio in dextrin-VA. The area of the three peaks, C1, C1$\mathrm{S} 2$ and $\mathrm{C} 1-\mathrm{S} 3$, was determined using a Lorentzian adjust, and the isomer ratios calculated. For dextrin-VA with DS $20 \%$ obtained by chemical reaction, an isomer ratio of 70:30, at positions 2 and 3 , was found. For the enzymatic reaction a similar substitution pattern was observed (the ratio of isomers at positions 2 and 3 was 76:24). Additionally, the regioisomer at position 2 was more highly favored (two times). Again, it appears that the enzyme does not influence the reaction, since the isomers obtained are the same, irrespective of the presence of the enzyme. Thus, this work demonstrates that it is possible to regioselectively modified dextrin without using enzymed.

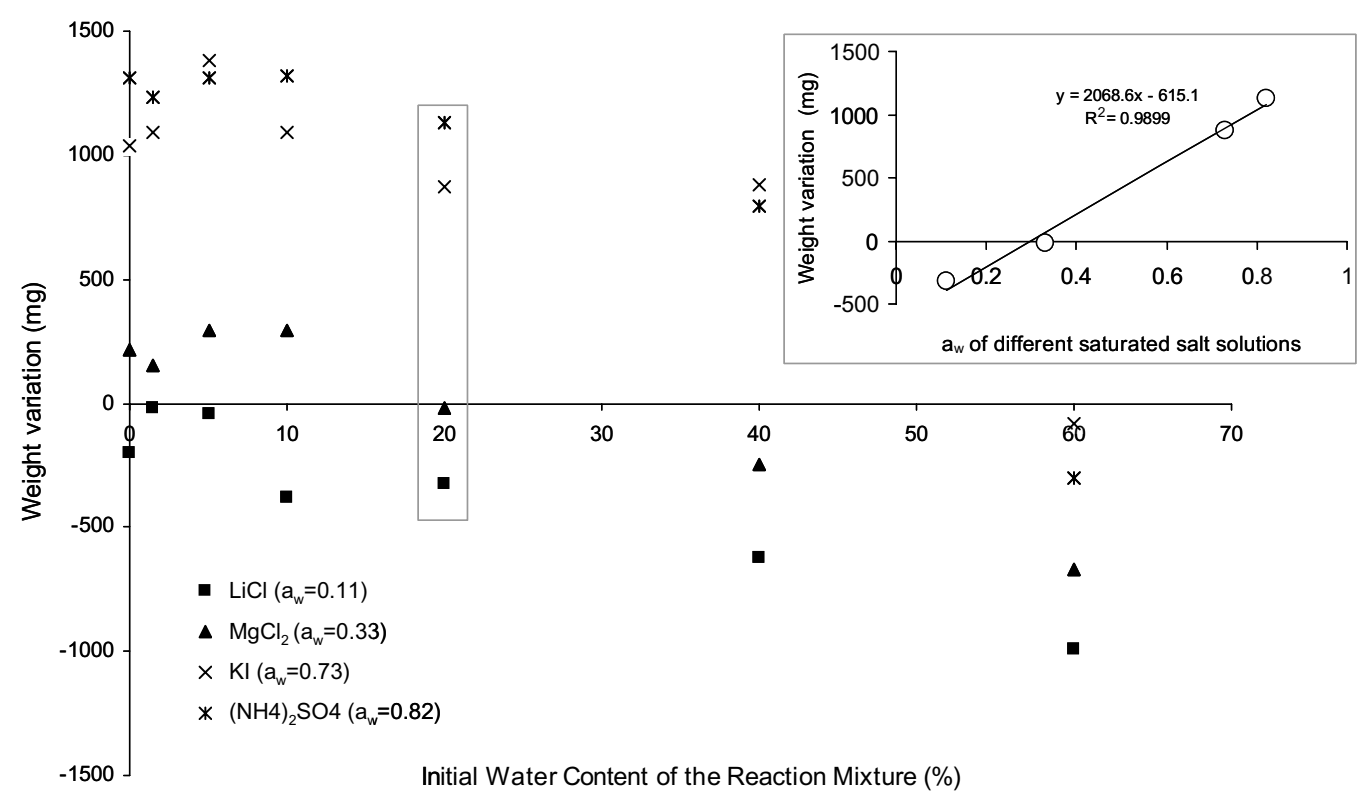

Fig. 3. Weight variation of the samples containing DMSO, VA and enzyme, with different initial water content, after equilibrium with saturated salt solutions. Insertion shows the $a_{\mathrm{w}}$ calculation $\left(a_{\mathrm{w}}=0.3\right.$, for $\left.y=0\right)$ for an initial water content of $20 \%$. 


\subsubsection{Effect of water amount and activity on the transesterification reaction}

The transesterification reaction was carried out using mixtures of DMSO with different amounts of water, corresponding to different values of $a_{\mathrm{w}}$ (Fig. 3). The values of $a_{\mathrm{w}}$ and the corresponding dextrin DS obtained are shown in Fig. 2 and Table 3. Table 3 shows that the reaction is switched towards synthesis for $a_{\mathrm{w}}<0.3$. Low amounts of water (in the range $0-20 \%$ ) correspond to similar $a_{\mathrm{w}}$, and lead to similar DS. Higher values of $a_{\mathrm{w}}$ $(\geqslant 0.4)$ result in a dramatic reduction of dextrin modification. These results are clearly different from the effect of $a_{\mathrm{w}}$ described by Ferreira et al. for the catalysed reaction, with dextran. In this case, a very low amount of water is mandatory for the enzymatic reaction to be carried out, while in our experiment (with dextrin) as much as $20 \%$ of water

Table 3

Water activity of reaction mixtures with different amounts of water and DS (the VA to dextrin ratio correspond to a theoretical DS of $20 \%$ ) obtained after transesterification reaction

\begin{tabular}{lcc}
\hline Water content $(\%)$ & Water $^{\text {activity }}$ & DS $(\%)^{\mathrm{b}}$ \\
\hline 0.015 & $0.22(0.11-0.33)$ & 17 \\
0.15 & $0.17(0.11-0.33)$ & 17 \\
5 & $0.15(0.11-0.33)$ & 18 \\
10 & $0.25(0.11-0.33)$ & 14 \\
20 & $0.30(0.11-0.33)$ & 14 \\
40 & $0.41(0.33-0.73)$ & 0 \\
60 & $0.95(0.82-1)$ & 0 \\
80 & 1 & 0 \\
100 & 1 & 0 \\
\hline
\end{tabular}

${ }^{\mathrm{a}} a_{\mathrm{w}}$ estimated as shown in Fig. 2. The actual $a_{\mathrm{w}}$ value is in the range between brackets.

b Degree of acrylate substitution (calculated as molar ratio of VA to dextrin glucopyranose residues in the reaction mixtures). $\left(a_{\mathrm{w}} \approx 0.3\right)$ may be present without loss of synthesis reaction.

\subsection{Hydrogel production and NMR characterization}

The acrylate groups in dextrin-VA were polymerized using APS and TEMED as free radical initiators. Aqueous solutions of dextrin-VA with different DS (ranging from ca. $10 \%$ to $70 \%$ ) and with two concentrations ( $33 \%$ and $44 \%(w / v))$, were polymerized at room temperature, and gelation occurred within less than $5 \mathrm{~min}$. The obtained hydrogel slabs were almost transparent, the opacity increasing with decreasing in DS values, which is likely related to the better solubility of the more highly substituted material.

The hydrogels were characterized using the solid state NMR technique of ${ }^{13} \mathrm{C} \mathrm{CP/MAS}$. This analysis, as described ahead, allowed the detection of VA adsorbed to dextrin, covalently linked to dextrin, and finally of the VA reticulating the hydrogel.

In the ${ }^{13} \mathrm{C} \mathrm{CP} / \mathrm{MAS}$ spectra of dextrin or similar samples, the peak chemical shifts are sufficiently similar to those observed in the solution state to allow peak assignment to be made. In order to identify the environments of non-linked dextrin and VA moieties, a sample of dextrin wetted with vinyl acrylate was prepared and analysed. The spectrum obtained (Fig. 4) clearly shows the glucopyranosyl carbons in the 58-110 ppm and the acrylate carbons in the $120-175 \mathrm{ppm}$ region. Signals at $90-105 \mathrm{ppm}$ and $58-65$ ppm are attributed to $\mathrm{C} 1$ and $\mathrm{C} 6$ carbons in hexapyranoses, respectively. The overlapping signal at about $68-78 \mathrm{ppm}$ is associated with C2, C3 and $\mathrm{C} 5$. The resonance that appears at $82 \mathrm{ppm}$ is

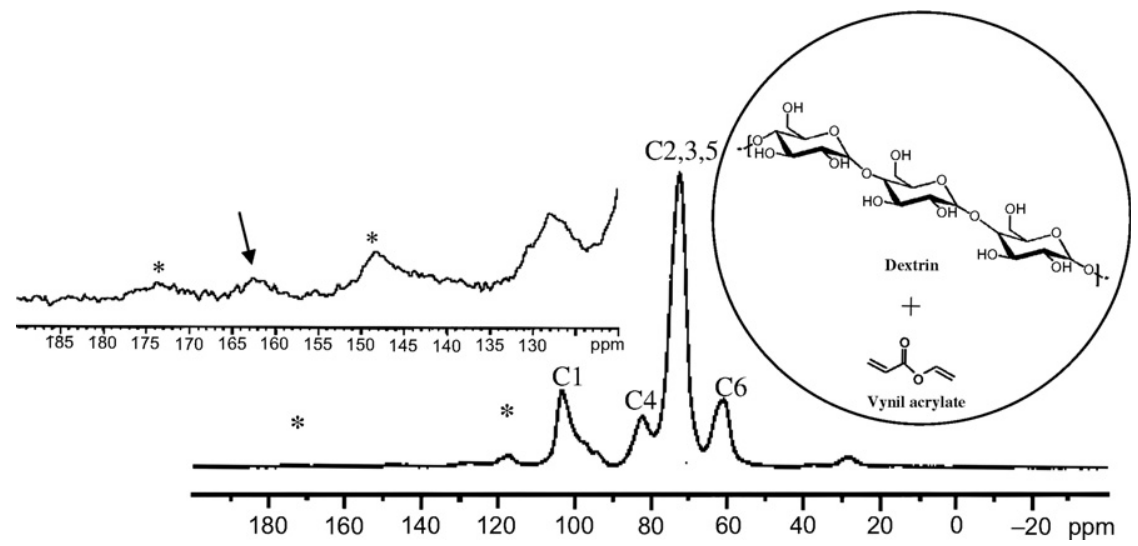

Fig. 4. ${ }^{13} \mathrm{C}$ CP-MAS NMR spectra of dextrin mixed with VA. Bands indicated with $*$ are spinning side bands. Number of scans $(\mathrm{NS})=16729$. 
thought to arise from $\mathrm{C} 4$ carbons in non-crystalline material [21]. Regarding VA carbons, the peak resonating at $128 \mathrm{ppm}$ arises from the carbons engaged in the double bond whereas the peak at $163 \mathrm{ppm}$ corresponds to the carbonyl carbons (arrow in Fig. 4). Both these positions should thus be characteristic of the VA environments when simply adsorbed to the dextrin. Fig. 5 shows the downfield expansions of the ${ }^{13} \mathrm{C} C \mathrm{CP}-\mathrm{MAS}$ NMR spectra of the same non-derivatized dextrin sample, together with those of samples of dextrin-VA obtained with different degrees of substitution.

It is clear that the transesterification reaction leads to a shift of the VA carbonyl resonance from $163 \mathrm{ppm}$ to $167 \mathrm{ppm}$. Indeed, and in spite of the relatively poor signal to noise ratio of the spectra (Fig. 5), the area of this signal was found to increase steadily with the degree of substitution. It is possible,

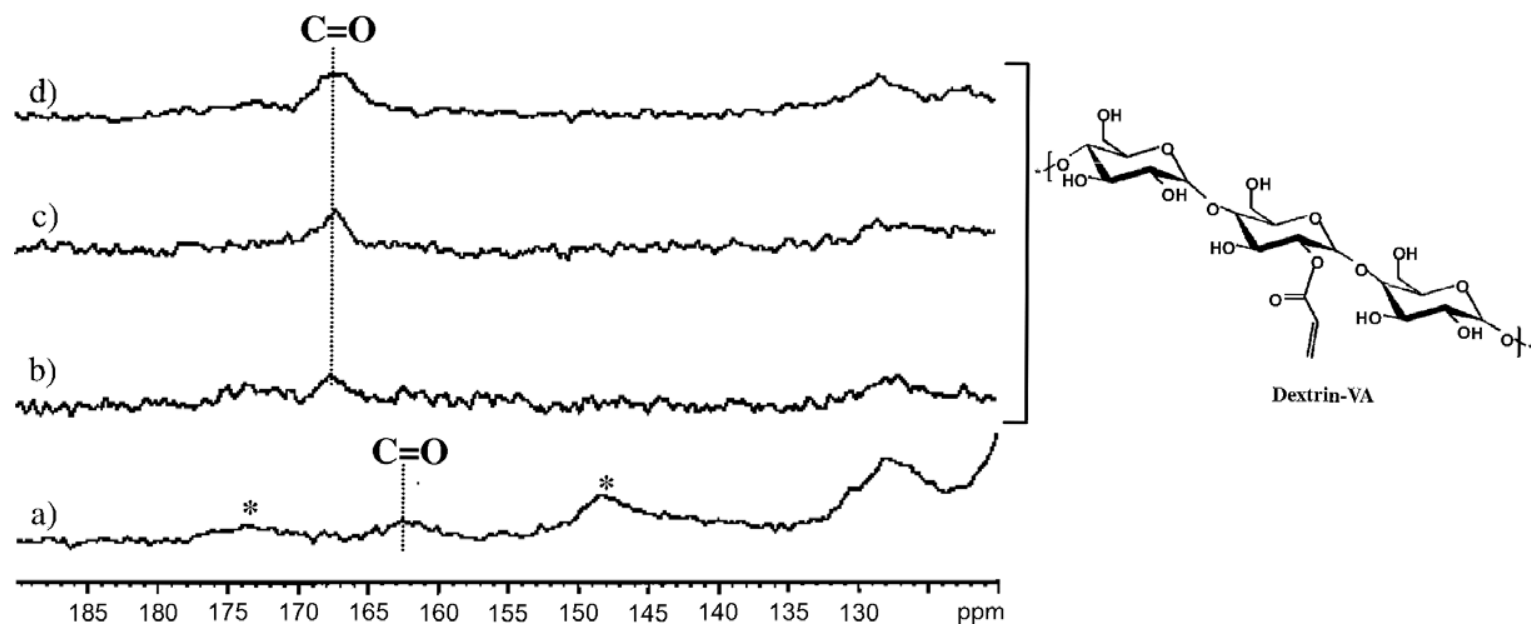

Fig. 5. Downfield expansions of the ${ }^{13} \mathrm{C}$ CP-MAS NMR spectra of (a) dextrin mixed with vinyl acrylate and dextrin-VA with different degrees of substitution (DS); (b) $6.6 \%$, NS =6228; (c) $8.7 \%$, NS =6706; (d) $15.3 \%$, NS = 18827; the degrees of substitution were determined by liquid state NMR of the solubilised dextrin-VA sample. Peaks indicated with $*$ are spinning side bands.

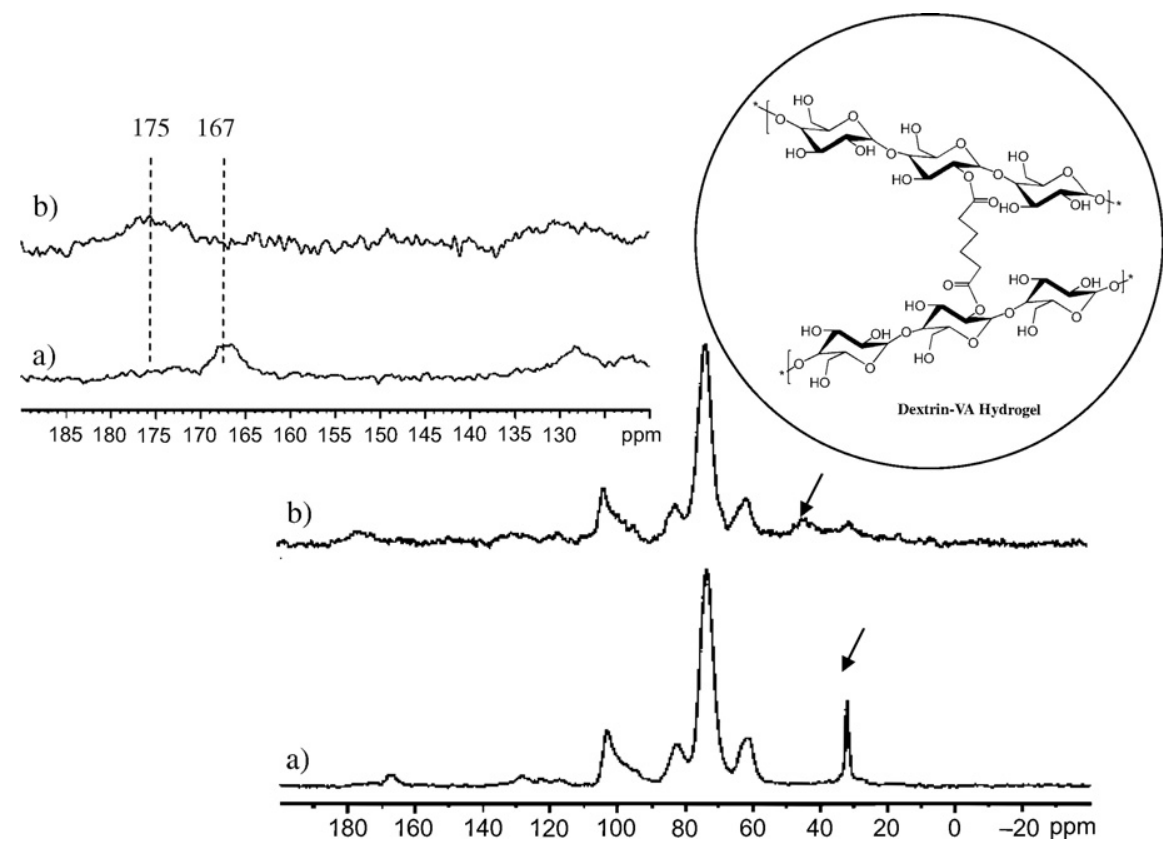

Fig. 6. Full ${ }^{13} \mathrm{C}$ CP-MAS NMR spectra and lowfield expansions for (a) dextrin-VA DS 15\%, NS = 18827; (b) dextrin-VA DS $15 \%$ hydrogel, NS $=62916$. 
therefore, to distinguish the grafted (167 ppm) and non-grafted $(163 \mathrm{ppm})$ acrylate groups, with basis on the CP-MAS spectra of the samples. In the course of dextrin-VA preparation, extensive dialysis is crucial for the effective removal of unreacted vinyl acrylate. The effectiveness of the dialysis could, thus, be evaluated by NMR of the consistent presence of the $163 \mathrm{ppm}$ environment (unreacted VA monomers), under conditions of incomplete dialysis.

The spectrum of dextrin-VA hydrogel (containing cross-linked acrylate groups) is shown in Fig. 6b. It is interesting to note that the carbonyl resonance is now broadened and shifted from $167 \mathrm{ppm}$ in dextrin-VA, to $175 \mathrm{ppm}$ in the hydrogel. The broadening reflects the heterogeneity of crosslinked VA environments and the lowfield shift results from the chemical changes taking place around the carbonyl groups upon the cross-linking process. The signal detected at $40 \mathrm{ppm}$ after polymerization is attributed to the $\mathrm{CH}_{2}$ (methylene) carbons of the cross-linked VA groups whereas the peak at $30 \mathrm{ppm}$ simply corresponds to residual DMSO (arrows in Fig. 6).

The peak at $167 \mathrm{ppm}$ completely disappears in the hydrogel spectrum (Fig. 6b), meaning that all grafted acrylate groups are involved in reticulation. When using a hydrogel prepared from a dextrin-VA with a higher degree of substitution (DS 67\%), it is possible to detected grafted acrylate groups not contributing to reticulation, since after polymerization, a peak at $167 \mathrm{ppm}$ is still present (Fig. 7). The possibility of using the NMR peak areas to quantify the

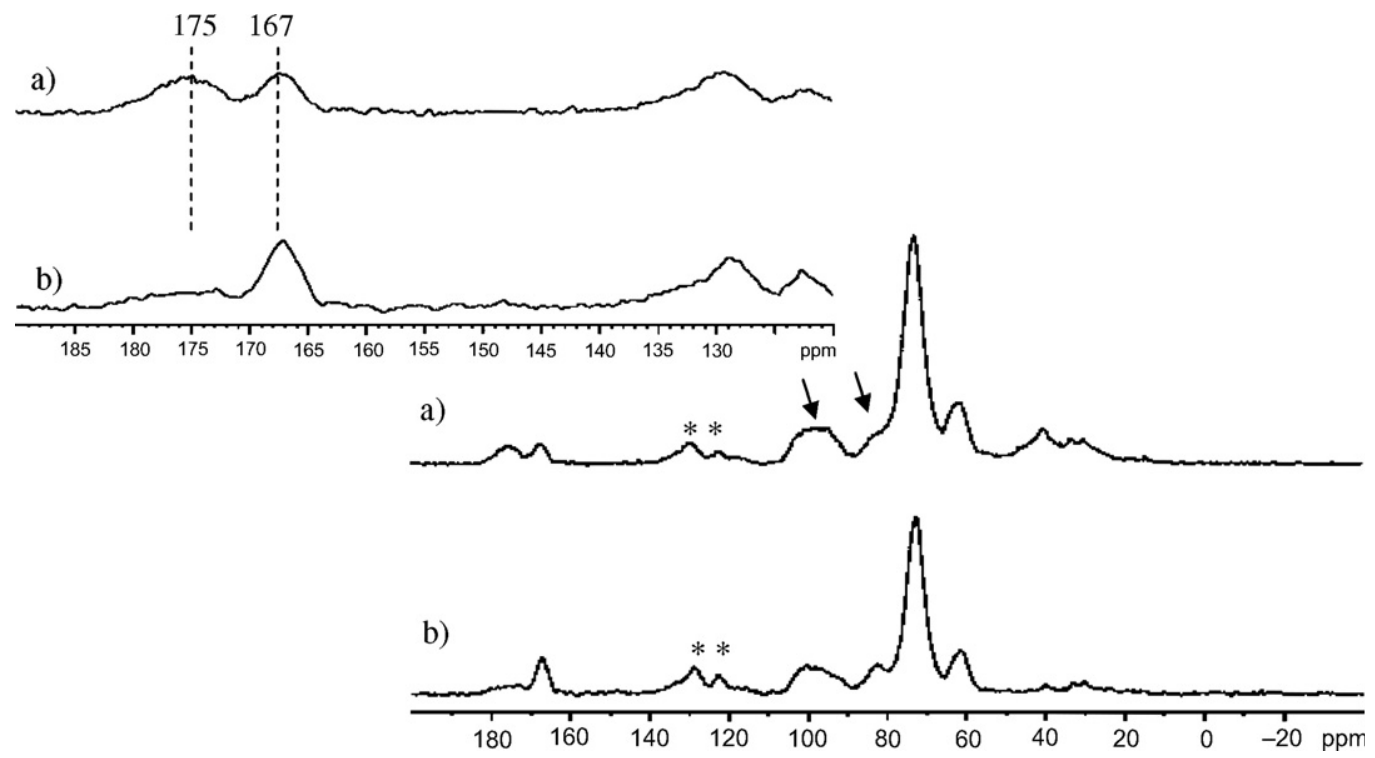

Fig. 7. Full ${ }^{13} \mathrm{C}$ CP-MAS NMR spectra and lowfield expansions for (a) dextrin-VA DS $=67 \%$, NS $=20821$; (b) dextrin-VA DS $=67 \%$ hydrogel, NS $=20898$. The signals indicated with $*$ correspond to spinning sidebands.
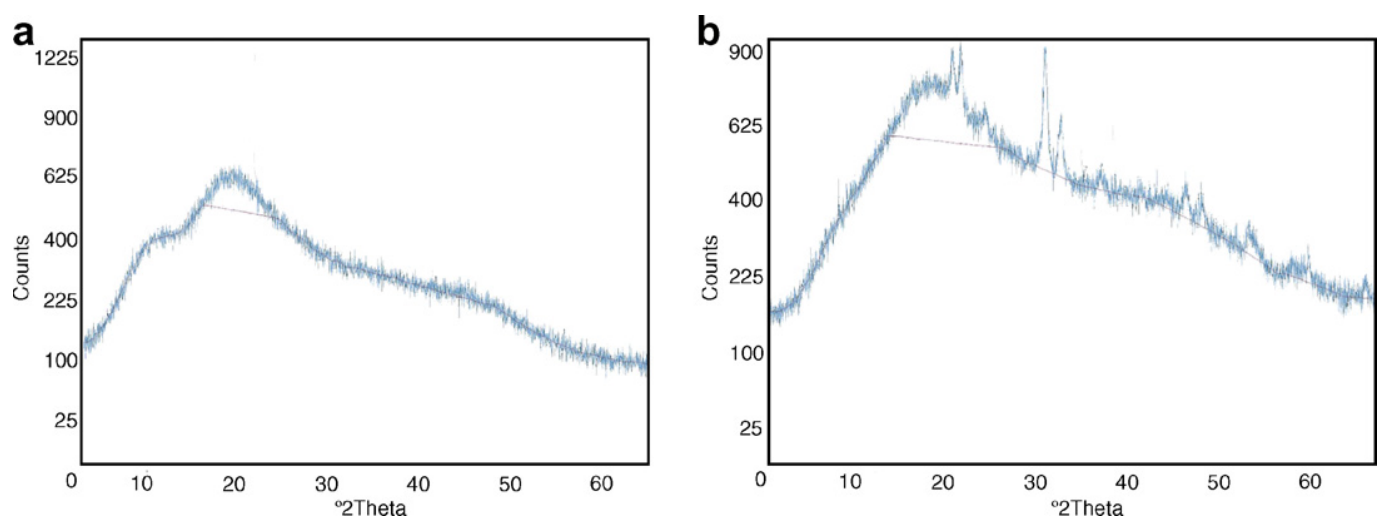

Fig. 8. X-ray powder diffraction patterns obtained from (a) dextrin-VA DS 67\%; (b) dextrin-VA DS $67 \%$ hydrogel. 
degree of reticulation (DR, percentage of grafted acrylate groups that are cross-linked) is currently being explored and will be reported in a subsequent paper. Possible structural differences in the polysaccharide involved in the two samples, dextrin-VA and the corresponding hydrogel, may be more easily detected using the hydrogel prepared with higher DS. The differences observed in the $\mathrm{C} 1$ and $\mathrm{C} 4$ dextrin resonances in the ${ }^{13} \mathrm{C}$ CP-MAS NMR spectra shown in Fig. 7 suggest that substantial conformational changes occur in the dextrin polymers in both materials. Indeed, the $\mathrm{C} 1$ and $\mathrm{C} 4$ resonances are broadened and displaced to higher field after polymerization (arrows in Fig. 7). These are the two carbon sites involved in glycosidic bonds and would therefore be expected to be the most sensitive to changes in the polysaccharide conformation. Furthermore, the broadening and shift to higher field of the $\mathrm{C} 4$ resonance have been interpreted before as indicative of an increase in polysaccharide crystallinity [22]. This could indeed be confirmed by the X-ray diffraction patterns of both samples (Fig. 8) which suggest an increase in polymer crystallinity as a result of reticulation.

\section{Conclusions}

A method previously developed by Ferreira et al. was in this work applied in the production of dextrin hydrogels. Surprisingly, it was verified that, although Proleather effectively catalyses the transesterification of acrylate molecules to dextran and inulin, dextrin is not a substrate for this enzyme. Nevertheless, it has been possible to produce dextrin with varying amounts of grafted acrylate groups, by varying the VA concentration. Also surprising was the finding that the regioselectivity of the non-catalysed reaction is comparable to the one obtained with the enzyme-catalysed reaction, $\mathrm{C} 2$ and $\mathrm{C} 3$ being the preferred acylation positions. Derivatized dextrin can be polymerized in aqueous solution by radical polymerization with APS and TEMED.

Combining the ability to tailor the hydrogel properties to fit a wide range of characteristics, with the biocompatibility of the starch-based materials, it is possible to obtain dextrin cross-linked networks which might be very attractive for biomedical applications. Although starch hydrogels have been reported by other authors, the approach used in this work is different, and the basis for a comprehensive NMR structural analysis has also been developed. Current work is in progress with the purpose of quantifying, through solid NMR analysis, the several kinds of VA present in the hydrogels. Rheological and biocompatibility studies have been performed and will be described elsewhere.

\section{References}

[1] Peppas NA, Bures P, Leobandung W, Ichikawa H. Hydrogels in pharmaceutical formulations. Eur J Pharm Biopharm 2000;50:27-46.

[2] Peppas NA. Hydrogels in: Biomaterials science: an introduction to materials in medicine. San Diego: Academic Press; 1996. p. 60-4.

[3] McCulloch I, Shalaby SW. Tailored polymeric materials for controlled delivery systems. Washington DC: American Chemical Society; 1998.

[4] Kane JB, Tompkins RG, Yarmush ML, Burke JF. Burn dressings in: Biomaterials science: an introduction to materials in medicine. San Diego: Academic Press; 1996. p. 360-70.

[5] Ishihara M, Nakanishi K, Ono K, Sato M, Saito Y, Yura H, et al. Photocrosslinkable chitosan as a dressing wound occlusion and accelerator in healing process. Biomaterials 2002;23:833-40.

[6] Chen T, Embree HD, Brown EM, Taylor MM, Payne GF. Enzyme-catalyzed gel formation of gelatine and chitosan potential for in situ applications. Biomaterials 2003;24 2831-41.

[7] Drury JL, Mooney DJ. Hydrogels for tissue engineering: scaffold variables and applications. Biomaterials 2003;24: 4337-51.

[8] Wong WH, Mooney DJ. Synthesis and properties of biodegradable polymers used as synthetic matrices for tissue engineering in: synthetic biodegradable polymer scaffolds. Birkhaüser: Boston; 1997. p. 51-82.

[9] Marques AP, Reis RL, Hunt JA. The biocompatibility of novel starch-based polymers and composites: in vitro studies. Biomaterials 2002;23(6):1471-8.

[10] Zhang L-M, Yang C, Yan L. Perspectives on: strategies to fabricate starchbased hydrogels with potential biomedical applications. J Bioact Compat Pol 2005;20(8):297-314.

[11] Ferreira L, Gil MH, Dordick JS. Enzymatic synthesis of inulin-containing hydrogels. Biomacromolecules 2002;3: 333-41.

[12] Ferreira L, Carvalho R, Gil MH, Dordick JS. Enzymatic synthesis of dextran-containing hydrogels. Biomaterials 2002;23:3957-67.

[13] Cooney CL, Hueter J. Enzyme catalysis in the presence of nonaqueous solvents using chloroperoxidase. Biotechnol Bioeng 1974;16(8):1045-53.

[14] Zacks A, Klibanov AM. Enzyme-catalyzed processes in organic solvents. Proc Natl Acad Sci USA 1985;82:3192-6.

[15] Klibanov AM. Why are enzymes less active in organic solvents than in water? Trends Biotechnol 1997;15:97-101.

[16] Klibanov AM. Improving enzymes by using them in organic solvents. Nature 2001;409(6817):241-6.

[17] Sergeeva MV, Paradkar VM, Bordick JS. Peptide synthesis using proteases dissolved in organic solvents. Enz Microb Technol 1997;20:263-8.

[18] Akkara JA, Ayyagari MSR, Bruno FF. Enzymatic synthesis and modification of polymers in nonaqueous solvents. TIBTECH Rev 1999;17:67-73. 
[19] Vervoort L, van den Mooter G, Augustijns P, Busson R, Toppet S, Kinget R. Inulin hydrogels as carriers for colonic drug targeting: I Synthesis and characterization of methacrylated insulin and hydrogel formation. Pharm Res 1997; 14(12):1730-7.

[20] Multon JL, Bizot H. Intermediate moisture foods and water activity determination. Ann Nutr Aliment 1978;32(2-3): 631-54.
[21] Langer R, Kost J, Shefer S, Shefer A. Structural characterization of starch networks in the solid state by crosspolarization magic-angle-spinning ${ }^{13} \mathrm{C}$ NMR spectroscopy and wide angle X-ray diffraction. Macromolecules 1992;25: 6756-60.

[22] Bociek SM, Gidley MJ. Molecular organization in starches: a ${ }^{13}$ C CP/MAS NMR. Study J Am Chem Soc 1985;107: 7040-4. 